\title{
Ability of Slovakian Pupils to Identify Birds
}

\author{
Pavol Prokop* and Rastislav Rodák \\ Trnava University, Trnava, * Slovak. Academy of Sciences, Bratislava, SLOV AKIA
}

A pupil's ability to identify common organisms is necessary for acquiring further knowledge of biology. We investigated how pupils were able to identify 25 bird species following their song, growth habits, or both features presented simultaneously. Just about $19 \%$ of birds were successfully identified by song, about $39 \%$ by growth habit, and $45 \%$ of birds were identified when pupils were allowed to hear their song and to see their growth habit simultaneously. Statistically significant correlation was found between visual and acoustical identification success which suggests that these two stimuli have an additive effect. This study provides direct support for the use of visual and acoustic features of animals when learning about birds in biology lessons.

Keywords: Bird, Biology Education, Identification, Taxonomy

\section{INTRODUCTION}

Environmental protection is one of the most important current issues and will only become more important as environmental problems such as the greenhouse effect, forest clear-cutting, and/or human population continues to increase (Erdogan, Kostova, \& Marcinkowski, 2009). Environmental knowledge is an essential precursor of attitude formation (Kaiser, Wolfing, \& Fuhrer, 1999). Kellert and Westervelt (1984) noted that the level of knowledge is one of several factors affecting attitudes in children. Environmental attitudes consequently influence environmental behavior which is an expected product of a successful environmental education program (Iozzi, 1989). Schools can play an important role in the formation of children's environmental knowledge and attitude (Barraza \& Walford, 2002; Prokop, Tuncer, \& Chudá, 2007b).

Pupils' knowledge about native animals and plants has been found to be inconsistent (Strommen, 1995) or even limited (Paraskevopoulos, Padeliadu, \& Zafiropoulos, 1998). Moreover, it seems that pupils are more interested in pets or garden plants than in wild

Correspondence to: Pavol Prokop, PhD in Biology Education, Department of Biology, Faculty of Education, Trnava University, Priemyselná 4, P.O. Box 9,

91843 Trnava, SLOV AKIA

E-mail:pavol.prokop@savba.sk animals and plants (Paraskevopoulos et al., 1998; Lindemann-Matthies, 2005).

Knowledge of taxonomy is a basic part of biology. Basic knowledge of (names) of common, as well as, some rare organisms can be considered necessary for further development of biology/environmental knowledge (Randler, 2008). Pupils' knowledge of naming organisms is limited mainly to plants (Bebbington, 2005), and little is known about pupils' abilities to name birds (Randler, 2008; 2009).

Slovakian $6^{\text {th }}$ graders (age 11/12) are learning zoology of vertebrates and invertebrates. They should be able to identify common native animals, to know their anatomy, morphology, and ecology. In contrast to plants, birds can be identified both through song and/or habit. Bird growth habit is the only feature which can be used when using biology textbooks as a learning tool, but supplementary material on CDs or MCs may also include bird song which can be used as supplementary material in traditional biological settings. Bird song might interact with pupils' personal knowledge of birds, and thus the effectiveness of pupils' learning about birds would increase. This relationship is quite important because formal knowledge about animals is associated with attitudes toward them (e.g. Prokop \& Tunnicliffe, 2008; Prokop, Kubiatko, \& Fančovičová, 2008). However, the role of bird song in pupils' abilities to identify birds has never been examined.

In this study, we manipulated bird growth habit and bird song to test Slovakian pupils' abilities to identify native birds. Moreover, we compare these abilities 
between elementary school children (age 10 - 15) and university students (biology majors) in order to investigate how basic knowledge of naming birds changes as the age of pupils increases.

\section{METHODS}

\section{Participants}

A total of 154 pupils from one elementary school (Žilina) ( $\mathrm{N}=110$ pupils) and from one university (Faculty of Education, Trnava) ( $=44$ students) participated in this study. Elementary school pupils were $10-15$ year old (mean age $=12.3$, grade $5-9$ ), with the same proportion of boys and girls (55/55). University students (38 girls and 6 boys) were $2^{\text {nd }}$ year students with the mean age of 21.2 years. All of them have been studying to become elementary and secondary school biology teachers. During the time that the experiment was conducted (November - February 2005/2006), none of the students had experience with any vertebrate zoology course taught at the university. These two distinct samples of students were chosen to investigate whether age of pupils influences their abilities to identify birds. It would be expected that experiences with birds increase linearly with age of pupils. If so, older pupils (here university students) should have better abilities to identify birds compared to younger pupils.

\section{Analysing Process}

We separately examined the effects of visual and acoustical stimuli (bird song and habit), and simultaneous effects of acoustical and visual stimuli on pupils' abilities to identify birds. Both elementary and university pupils were randomly assigned to three treatments: 'Song', 'Picture' and 'Song + Picture' treatment (Table 1). Pupils in Song treatment were allowed to identify typical songs of 25 bird species (acoustic identification) and then pictures (visual identification) of the same 25 bird species. A reverse procedure was used in Picture treatment, where pupils were first allowed to identify bird pictures, and bird song immediately after. These two treatments were conducted in order to minimize potential effect of sequence of identification of method (visual and acoustical) used in the experiment. Bird species used either for acoustic or visual identification were the same, but the order of the species presented visually was different than the order of birds presented acoustically. Pupils were not told about the similarity of bird species used for visual and acoustical identification. This was done in order to maximize the pupils' effort to identify birds independently from the previous treatment. As could be expected, statistical analyses failed to reveal any differences in pupils' identification success between these two treatments, therefore pooled data from Picture and Song treatment were used in further analyses. Also, pupils from these two treatments were presented as a single sample consisting of pupils that identified birds either visually or acoustically.

\section{Implementations}

Pupils from Song + Picture treatment were allowed to identify 25 bird species used in previous treatments following their visual and acoustic features, and these were presented simultaneously. Bird identification was conducted in each treatment for a single occasion. Randomly chosen pupils from the elementary school and a whole sample of all second year university students individually used a personal computer in a separate classroom in which presentation of bird species (either visual or acoustical) was started. The length of presentation of each bird species was the same (approximately 60 seconds), and the presentation was repeated once. Each pupil received either two (Song + Picture treatment) or three (Picture, Song treatments)

Table 1. Distribution of participants within experimental treatment groups. Values denote the number of participants.

\begin{tabular}{|c|c|c|c|c|c|c|c|}
\hline \multicolumn{2}{|l|}{ School } & \multicolumn{6}{|c|}{ Grade } \\
\hline \multirow{5}{*}{ 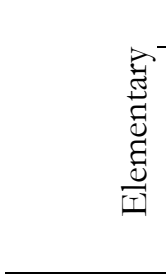 } & Treatment & 5 & 6 & 7 & 8 & 9 & Total \\
\hline & Song, than Picture & 6 & 12 & 9 & 8 & 6 & 41 \\
\hline & Picture, than Song & 6 & 8 & 7 & 9 & 6 & 36 \\
\hline & Song + Picture & 6 & 10 & 5 & 3 & 9 & 33 \\
\hline & Total & 18 & 30 & 21 & 20 & 21 & 110 \\
\hline \multirow{4}{*}{ 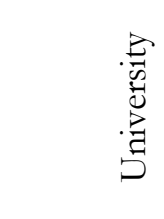 } & Song, than Picture & - & - & - & - & - & 14 \\
\hline & Picture, than Song & - & - & - & - & - & 19 \\
\hline & Song + Picture & - & - & - & - & - & 11 \\
\hline & Total & - & - & - & - & - & 44 \\
\hline
\end{tabular}


sheets of paper with questions which ascertained several details such as age, grade, or gender on the first sheet. Following sheet(s) of paper contained numbers and columns in which bird species were noted by the participants in accordance with whether they were identified by song (sheet 2) or by picture (sheet 3 ) or by both stimuli (only sheet 2 for Song + Picture treatment).

The pictures and songs of birds were taken from the CD of the original publication of the Ministry of Education, Slovak Republic (Živá príroda, 2001). This publication was originally developed as supplementary didactic material for teaching biology in Slovakian elementary or secondary schools and contains sounds of 90 animals including insects, amphibians, birds, and mammals and approximately a similar number of animal pictures. Pictures of birds contain both male and a female (except species in which sexual dimorphism is weak, e.g. goldfinch Carduelis carduelis or the black-billed magpie Pica pica) and an egg of each particular species. Almost all presented birds except the black stork, kingfisher and eagle owl can be considered relative common in Slovakia (Danko, Darolová, \& Krištín, 2002).

\section{RESULTS}

\section{Consistency of pupils' responses}

Each pupil's success at bird identification was binomially coded (true $=1$, false $=0$ ) which allowed us to calculate the consistency of pupils' responses. Data from both university and elementary school student samples were pooled for the subsequent analysis.

Cronbach's alpha coefficient commonly used for calculation of reliability (Nunnaly, 1978) showed a relatively high consistency just for the Picture $(\alpha=0.66)$ and Song + Picture $(\alpha=0.67)$ treatments. In contrast, Song treatment showed the lowest consistency of pupils' responses $(\alpha=0.38)$. These values suggest that pupils were relatively more certain when looking at bird pictures than when only hearing the bird song.

\section{Acoustical versus visual identification of birds}

Figure 1 shows the distribution of pupils (pooled data from elementary school and university sample) that successfully identified birds acoustically, visually, or in combination of both stimuli (acoustically + visually, Song + Picture treatment). Most pupils identified only about $10-28 \%$ of 25 bird species when hearing only its song. In contrast, the majority of pupils were able to identify about $30-48 \%$ of all birds following their pictures being shown. Interestingly, pupils from the Song + Picture treatment group seem to be most successful, because most of them identified $48-60 \%$ of birds. More detailed data is shown in Appendix A. While mean identification success following bird song (pooled data from Picture and Song treatment) was about $19 \%$, identification success following bird pictures (pooled data from Picture and Song treatment) was $39 \%$ and Song + Picture treatment (i.e. combination of acoustic and visual features) had a $45 \%$ success rate.

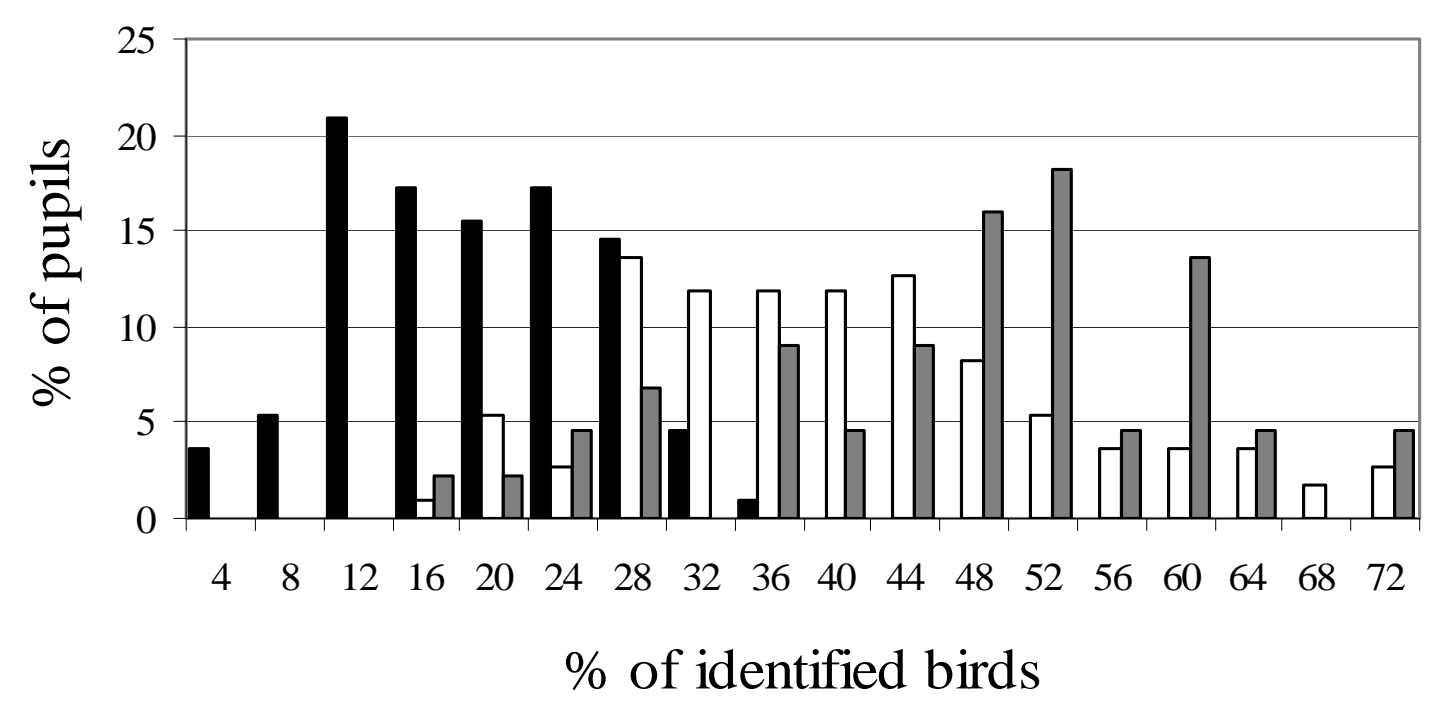

Figure 1. Distribution of pupils that successfully identified birds following song (black bars), pictures (open bars) or both song and picture (grey bars). Pooled data from elementary school and university samples are shown. 
Only two birds were better identified by song than by the picture (cuckoo and crow). 7 of 25 birds were significantly better identified in Song + Picture than only from pictures: blackbird, hooded crow, turtle dove, cuckoo, sky lark, black woodpecker and black-headed gull. This would suggest that acoustic stimuli partly supply visual stimuli which explain the relatively higher success in bird identification for Song + Picture treatment where combination of visual and acoustic stimuli was used.

The best known bird species identified only visually were woodpecker, house swallow, black stork and great tit (all were identified by more than $80 \%$ of pupils) (Appendix A). Surprisingly, notoriously common birds such as the magpie, blackbird, and kestrel were unknown to about two-thirds of participants. The

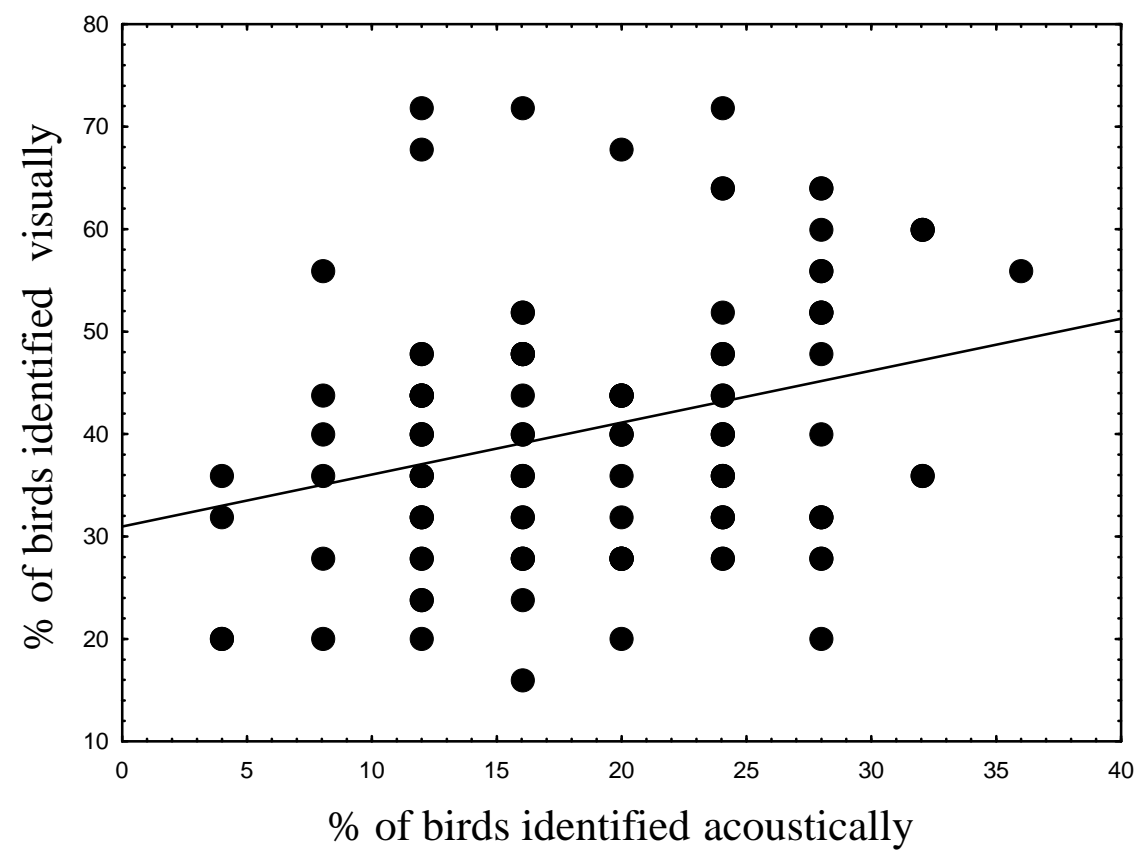

Figure 2. Linear relationship between pupils' abilities to identify birds following acoustic and visual stimuli $(\mathrm{r}=0.31, \mathrm{y}=30.9773+0.507 \mathrm{x}, \mathrm{p}<0.001, \mathrm{n}=110)$.

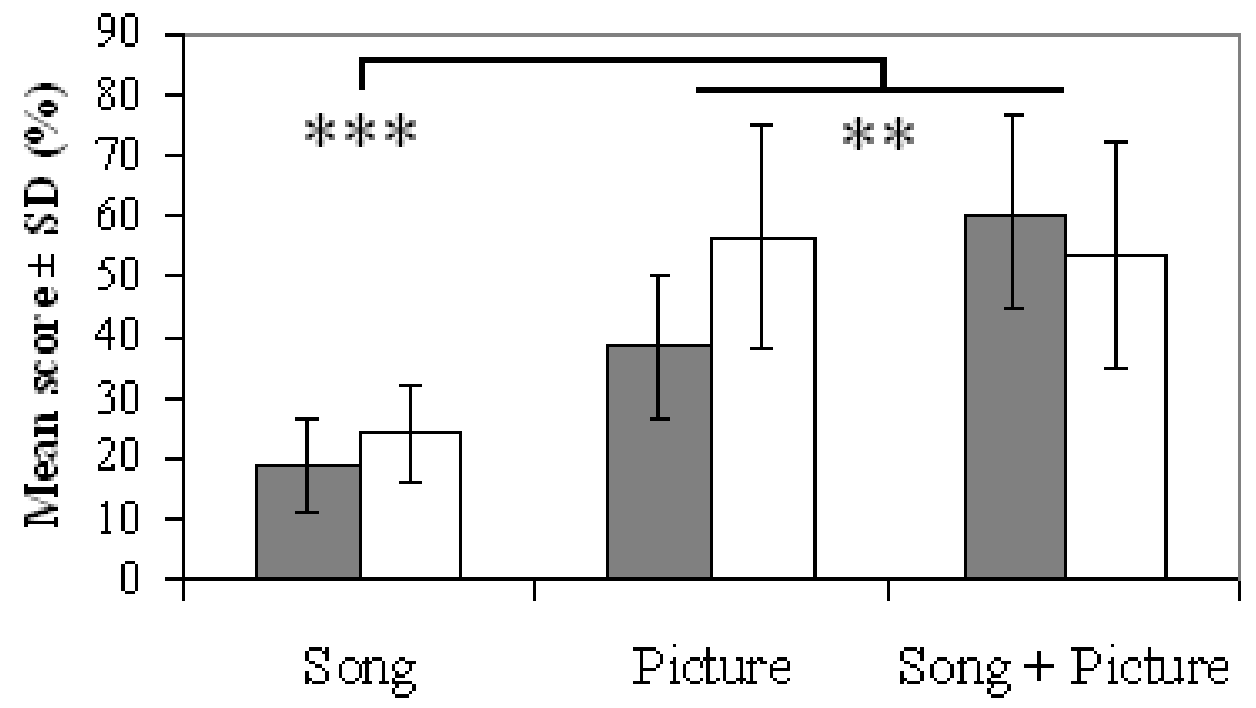

Method of identification

Figure 3. Mean differences in bird identification success with respect to type of school and method of bird identification. Elementary school denotes grey bars, university denotes open bars. Differences were calculated by ANOVA. $* * p<0.01, * * * p<0.001$ 
sympatric black blackstart and multicoloured goldfinch were virtually unknown. Moreover, about $30 \%$ of pupils failed to identify the house sparrow, which is sympatric, probably the most common bird in Slovakia. Slovak names of birds are strictly binomial. It is also important to note that pupils were generally unable to provide both names of identified birds.

In order to examine whether any relationship between pupils' abilities to identify birds following visual and acoustic stimuli exists, we performed a calculation of correlation coefficients between each pupil's visual and acoustical success within Song and Picture treatments. Song + Picture treatment was omitted, because only one set of data were obtained. Figure 2 shows that the relationship between pupils' abilities to identify birds following acoustic and visual stimuli is significant $(p<0.001)$. This suggests that pupils' abilities to identify birds through visual or acoustic features are not mutually exclusive, and their additive character could explain a relatively better success rate of pupils from the Song + Picture treatment, where both acoustic and visual stimuli have been presented simultaneously.

\section{Elementary school versus university: is there any difference?}

Differences in mean success of bird identification between elementary school and university students are shown in Figure 3. Factorial analysis of variance (ANOVA) was used to examine effect of school type and treatment effects on bird identification success. Method of bird identification $(\phi<0.0001)$, but no type of school per se $(p=0.77)$ was found to be the only significant factor influencing pupils' success in bird identification. The Tukey HSD post-hoc ANOVA test that examines differences in detail, showed that the difference between pupils' success when identify birds visually (data from Picture and Song treatments) versus Song + Picture treatment (combination of acoustic and visual stimuli) were significant at $p<0.01$ (Figure 3), whereas the latter treatment scored better. Acoustic identification of birds received lowest success in comparison with the other two treatments (both $p<$ 0.001). Also, the pupils from Song + Picture treatment gained significantly higher scores than pupils which identified birds visually, independently from bird song (Picture and Song treatments), only in the elementary school sample (Tukey HSD post-hoc test, $p<0.01$ ), but no similar pattern was found for the university students (visual identification vs. Song + Picture treatment, $p=$ 0.99). We suggest that limited sample size for the Song + Picture treatment in the university sample $(n=11)$ could partly camouflage weak differences between visual identification versus Song + Picture treatment in university students. Gender differences, in any case, were not apparent.

\section{DISCUSSION}

Birds are animals with conspicuous habits, but also songs that cannot be overlooked. Traditional biology settings use only textbooks or additional pictures of animals ignoring their acoustic signals. As far as we know, this is the first study which investigated the importance of visual and acoustic stimuli in biology education. Previous research in pupils' abilities to identify birds used only visual stimuli leaving acoustic stimuli unexamined (e.g. Randler \& Bogner, 2002; Prokop, Kubiatko, \& Fančovičová, 2007a; Randler, 2009). We found out that, at least for the elementary school pupils, acoustic signals can help the pupil to identify birds more successfully than when only visual features are used. Our data supports the idea that some birds have familiar songs, such as the cuckoo, which are more noticeable than bird growth habits. These species can be more easily identified acoustically than visually. We also propose that pupils can build independent concepts of some birds following their song and growth habit. For example, when pupils looked at a picture of a blackbird, they were not very familiar with it, even though the blackbird is a common sympatric bird included in $6^{\text {th }}$ grade biology textbooks, and every pupil must know that something like a blackbird exists. However, students hearing its song were often quoted:

"I have heard this bird usually in the early morning

somewhere around my home", or "I know the song of this

bird, but I do not know what it looks like" etc.

Perhaps surprisingly, identification skills of elementary school pupils and biology majors did not significantly differ. Interestingly, Randler (2009) also reported similar success (about 40\%) of bird identification through visual stimuli in primary children (grade 2 -4). This supports the idea that knowledge of biology on this topic is rapidly acquired before the age of 10 (Carey, 1985; Jaakola \& Slaughter, 2002) and further acquirement is somewhat slower. This phenomenon can be explained by current high school biology curricula that are not directed on pupil identification skills of either animals or plants. Instead, they are focused mainly on animal anatomy, physiology, or higher taxonomy.

Learning is obviously crucial for the way in which children acquire biological concepts (Reiss \& Tunnicliffe, 1999). Perhaps surprisingly, children of all ages seem to learn more about the names and classification of animals from their homes and from direct out-of-school observations, than from school, books, or other media (Tunnicliffe \& Reiss, 1999). The role of school in learning about animals should not be overlooked, but, the efficacy of the learning process 
should be improved. Especially the use of taxidermic bird specimens was shown to provide better educational tools than slides with regard to long-term training of identification skills in $10-12$ year old pupils (Randler \& Bogner, 2002). Learning outside school also provided a significant increase of pupil knowledge of birds, as was currently demonstrated on pupils visiting ornithological stations (Brossard, Lewenstein, \& Bonney, 2005). Informal learning may therefore greatly help to develop pupil identification skills and knowledge about birds.

\section{Educational implications}

Direct educational implications emerged from the present study. First, the use of slides alone is less effective than simultaneous use of acoustic signals, at least when teaching pupils about birds. Acoustic signals may help children identify birds more easily, and the concepts about particular bird species will therefore develop more effectively. Second, more attention should be focused on pupils' abilities to identify birds. Many common, or even heavily endangered birds, are unknown to the majority of children. Third, reevaluation of high school biology curricula in Slovakia (in terms of increasing pupils' identification skills) is necessary. Knowledge in anatomy, morphology, and/or evolution should not be acquired without pupils' basic experiences with living organisms.

\section{REFERENCES}

Barraza, L., \& Walford, R. A. (2002) Environmental education: A comparison between English and Mexican school children. Environmental Education Research, 8(2), $171-186$.

Bebbington, A. (2005) The ability of A-level student to name plants. Journal of Biological Education, 32(2), $62-67$.

Brossard, D., Lewenstein, B., \& Bonney, R. (2005) Scientific knowledge and attitude change: The impact of a citizen science project. International Journal of Science Education, 27, $1099-1121$.

Carey, S. (1985) Conceptual change in childhood. Cambridge, MA: MIT Press.

Danko, Š., Darolová A., \& Krištín A. (Eds.) (2002) Rozšírenie vtákov na Slovensku. [Distribution of birds in Slovakia]. VEDA, Bratislava

Erdogan, M., Kostova, Z., Marcinkowski, T. (2009) Components of environmental literacy in elementary science education in Bulgaria and Turkey. Eurasia Journal of Mathematics, Science \& Technology Education, 5(1), 15 26.

Iozzi, L. A. (1989) What research says to the educator. Part one: Environmental education and the affective domain. Journal of Environmental Education, 20(3), 3 - 9.

Jaakkola, R. O., \& Slaughter, V. (2002) Children's body knowledge: Understanding 'life'as a biological goal. British Journal of Developmental Psychology, 20(3), 325 - 342.
Kaiser, F. G., Wolfing, S., \& Fuhrer, U. (1999) Environmental attitude and ecological behaviour. Journal of Environmental Psychology, 19(1), 1 - 19.

Kellert, S. R., \& Westervelt, M. O. (1984) Children's attitudes, knowledge and behaviors towards animals. Children's Environments Quarterly, 1(3), 8 - 11.

Lindemann-Matthies, P. (2005) 'Loveable' mammals and 'lifeless' plants: how children's interest in common local organisms can be enhanced through observation of nature. International Journal of Science Education, 27(6), 655 -677 .

Nunnaly, J. (1978) Psychometric theory. New York: McGrawHill.

Paraskevopoulos, S., Padeliadu, S., \& Zafiropoulos, K. (1998) Environmental knowledge of elementary school students in Greece. Journal of Environmental Education, 29(3), $55-61$.

Prokop, P., Kubiatko, M., \& Fančovičová, J. (2007a) Why do cocks crow? Children's concepts about birds. Research in Science Education, 37(4), 393 - 405.

Prokop, P., Tuncer, G., \& Chudá, J. (2007b) Slovakian students' attitude toward biology. Eurasia Journal of Mathematics, Science \& Technology Education, 3(4), 287 295.

Prokop, P., Kubiatko, M., \& Fančovičová, J. (2008) Slovakian pupils' knowledge of and attitudes toward birds. Anthrozoös, 21(3), 221 - 235.

Prokop, P. \& Tunnicliffe, S. D. (2008) "Disgusting animals": Primary school children's attitudes and myths of bats and spiders. Eurasia Journal of Mathematics, Science \& Technology Education, 4(2), 87 - 97.

Randler, C. (2008) Teaching species identification - a prerequisite for learning biodiversity and understanding ecology. Eurasia Journal of Mathematics, Science and Technology Education, 4(3), 223 - 231.

Randler, C. (2009) Learning about bird species on the primary level. Journal of Science Education and Technology, DOI 10.1007/s10956-008-9139-x

Randler, C., \& Bogner, F. (2002) Comparing methods of instruction using bird species identification skills as indicators. Journal of Biological Education, 36(4), 181 - 18

Reiss, M. J., \& Tunnicliffe, S. D. (1999) Conceptual development. Journal of Biological Education, 34, 13 - 16.

Strommen, E. (1995) Children's conceptions of forests and their inhabitants. Journal of Research in Science Teaching, 32(7), $683-698$.

Tunnicliffe, S. D. \& Reiss, M. J. (1999) Building a model of the enviroment: how do children see animals? Journal of Biological Education, 33(4), 142 - 148.

Živá príroda (2001). Slovenská agentúra životného prostredia, Slovensko [Living nature: Slovak Agency of Environment, Slovakia].

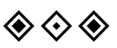


Appendix A. Pupils' success at bird identification with regard to the kind of identification method. Asterisks denote significantly higher identification success (as calculated by chi-square test) when comparing the Picture and Song + Picture treatment. Pooled data from elementary school and university sample are shown. $* p<0.05, * * p<0.01, * * * p<0.001$

\begin{tabular}{|c|c|c|c|c|}
\hline \multirow[b]{3}{*}{ Bird species } & \multirow{2}{*}{\multicolumn{4}{|c|}{ Method of identification }} \\
\hline & & & & \\
\hline & Latin name & Song $\%$ & Picture $\%$ & Song + Picture $\%$ \\
\hline Jay & Garrulus glandarius & 0.91 & 29.09 & 34.09 \\
\hline House Martin & Delichon urbica & 0 & 24.54 & 18.18 \\
\hline Black Stork & Ciconia nigra & 0 & 80 & 70.45 \\
\hline Kestrel & Falco tinnunculus & 4.55 & 26.36 & 34.09 \\
\hline Kingfisher & Alcedo attis & 26.36 & 54.54 & 52.27 \\
\hline Great-Spotted Woodpecker & Dendrocopos major & 72.73 & 92.72 & 93.18 \\
\hline Blackbird & Turdus merula* & 10.91 & 30 & 50 \\
\hline Swallow & Hirundo rustica & 12.73 & 92.72 & 97.72 \\
\hline Sky Lark & Alauda arvensis* & 2.73 & 1.81 & 9.36 \\
\hline Eagle Owl & Bubo bubo & 19.09 & 35.45 & 22.72 \\
\hline Green Woodpecker & Picus viridis & 0 & 9.09 & 9.09 \\
\hline Chaffinch & Fringilla coelebs & 0 & 11.81 & 9.09 \\
\hline Hooded Crow & Corvus corone cornix*** & 80 & 26.36 & 65.9 \\
\hline Great Tit & Parus major & 14.55 & 87.27 & 75 \\
\hline Black Redstart & Phoenicurus ochruros & 0 & 0 & 2.27 \\
\hline Black Woodpecker & Dryocopus martius** & 62.73 & 74.54 & 93.18 \\
\hline Pheasant & Phasianus colchicus & 29.09 & 100 & 95.45 \\
\hline Robin & Erithacus rubecula & 12.73 & 10 & 11.36 \\
\hline Cuckoo & Cuculus canorus*** & 89.09 & 37.27 & 97.72 \\
\hline Black-billed Magpie & Pica pica & 11.82 & 20.09 & 31.81 \\
\hline Hoopoe & Upupa ерорs & I.82 & 20 & 9.09 \\
\hline Goldfinch & Carduelis carduelis & 0 & 0.9 & 0 \\
\hline Turtle Dove & Streptopelia turtur** & 7.27 & 9.09 & 25 \\
\hline Black-headed Gull & Larus ridibundus** & 0.91 & 37.27 & 59.09 \\
\hline House Sparrow & Passer domesticus & 8.18 & 70.9 & 63.63 \\
\hline Mean success & - & 18.73 & 39.3 & 45.26 \\
\hline
\end{tabular}

